\title{
Transthyretin amyloid cardiomyopathy in women: frequency, characteristics, and diagnostic challenges
}

\author{
Marianna Bruno $^{1}$ • Adam Castaño ${ }^{1}$ - Arianna Burton ${ }^{1}$ • Justin L. Grodin ${ }^{2,3}$ \\ Published online: 14 August 2020 \\ (C) The Author(s) 2020
}

\begin{abstract}
Transthyretin amyloid cardiomyopathy (ATTR-CM) is a progressive, life-threatening disease characterized by deposition of insoluble amyloid fibrils in the myocardium, resulting in cardiac structural and functional abnormalities and ultimately heart failure. Disease frequency is reportedly lower in women than men, but sex-related differences have not been well established. We conducted a systematic literature review (SLR), based on PRISMA-P guidelines and registered with PROSPERO, to assess whether the epidemiology and clinical presentation of ATTR-CM differ between women and men. MEDLINE, Embase, and Cochrane databases and selected conference proceedings were searched (August 16, 2019) to identify observational and clinical studies reporting sex-specific data for patients with wild-type or hereditary ATTR-CM. Of 193 publications satisfying final eligibility criteria, 69 studies were included in our pooled analysis. Among the 4669 patients with ATTR-CM analyzed, 791 $(17 \%)$ were women, including $174(9 \%), 366$ (29\%), and 251 (18\%) in studies of wild-type, hereditary, and undefined ATTR$\mathrm{CM}$, respectively. Data available on disease characteristics were limited and very heterogeneous, but trends suggested some cardiac structural/functional differences, i.e., lower interventricular septal and posterior wall thickness and left ventricular (LV) end diastolic diameter, and higher LV ejection fractions, in women versus men across ATTR-CM subtypes. Because LV wall thickness $>12 \mathrm{~mm}$ is generally the suggested threshold for ATTR-CM diagnosis in both sexes, smaller cardiac anatomy in women with the disease may lead to underdiagnosis. Additional research and studies are needed to elucidate potential disparities between sexes in ATTR-CM frequency, clinical characteristics, and underlying biological mechanisms. This study was registered within the International Prospective Register of Systematic Reviews (PROSPERO) database of the University of York (CRD42019146995).
\end{abstract}

Keywords Transthyretin amyloid cardiomyopathy $\cdot$ Heart failure $\cdot$ Epidemiology $\cdot$ Diagnosis $\cdot$ Sex

\section{Introduction}

Transthyretin amyloid cardiomyopathy (ATTR-CM) is a progressive, often underdiagnosed and misdiagnosed disease caused by the extracellular deposition of misfolded

Electronic supplementary material The online version of this article (https://doi.org/10.1007/s10741-020-10010-8) contains supplementary material, which is available to authorized users.

Justin L. Grodin

Justin.Grodin@UTSouthwestern.edu

Medical Affairs, Pfizer Inc., New York, NY, USA

2 Department of Internal Medicine, University of Texas Southwestern Medical Center, Dallas, TX, USA

3 Clinical Heart and Vascular Center, University of Texas Southwestern Medical Center, 5323 Harry Hines Blvd, Suite E5.310F, Dallas, TX 75390-8830, USA transthyretin protein (TTR) that forms insoluble amyloid fibrils in organs and tissues [1]. Infiltration of the myocardium by amyloid fibrils ultimately results in life-threatening cardiac structural and functional abnormalities and heart failure [1-3]. The condition may be inherited as an autosomal dominant trait associated with mutations of the transthyretin gene TTR (hereditary ATTR-CM) or caused by age-dependent, nonmutational mechanisms (wild-type ATTR-CM). The prevalence of hereditary ATTR-CM varies by region due to fluctuating geographic distribution of TTR mutations; the Val122lle mutation, the most common in the USA, has been reported in approximately 3-4\% of African Americans [4]. Among hospitalized patients with heart failure and preserved ejection fraction, older than 60 years of age, with left ventricular wall thickness of $12 \mathrm{~mm}$ or greater on scintigraphy, the prevalence of wild-type ATTR-CM was 13\% [5]. The frequency of ATTR-CM, particularly the wild-type form, is reportedly lower in women than men [6-11], and the female sex has been 
proposed as a protective factor [1]. However, the higher proportions (over 50\%) of women with wild-type ATTR observed in some study populations $[5,12]$ provide theoretical support that ATTR-CM may be further underdiagnosed and/ or misdiagnosed in women because of sex-related differences in clinical presentation or disease characteristics [7, 13].

Given the availability of definitive treatments for ATTR$\mathrm{CM}$, early diagnosis in women, as in all patients, is critical to slowing disease progression and improving outcomes before overt multi-organ dysfunction ensues [13-17]. Despite the multiple diagnostic imaging options currently available, including advanced techniques such as nuclear scintigraphy that allow non-invasive assessment in select populations, and expert consensus recommendations for their use in ATTR-CM $[18,19]$, diagnosis of the disease remains a challenge. Clinicians' awareness of cardiac and non-cardiac clinical signs and symptoms, such as unexplained increases in left ventricular (LV) wall thickness on echocardiography, atrial fibrillation, bilateral carpal tunnel syndrome, and lumbar spinal stenosis, should raise suspicion of ATTR-CM and help facilitate prompt diagnosis [7]. However, the presumption of male predominance of wild-type and hereditary ATTR-CM may lower clinical suspicion of the disease when such "red flags" are observed in women.

We conducted a systematic literature review (SLR) to examine the epidemiology of ATTR-CM in women, to evaluate whether the clinical presentation and characteristics of the disease differ between women and men, and to explore potential reasons for these differences.

\section{Methods}

The SLR was designed to identify studies that reported sexspecific findings for patients with ATTR-CM, including wildtype and hereditary subtypes. The SLR was conceived and conducted according to the Preferred Reporting Items for Systematic Reviews and Meta-Analyses Protocol (PRISMAP) guidelines [20] and was registered within the International Prospective Register of Systematic Reviews (PROSPERO) database of the University of York (CRD42019146995) [21].

\section{Search strategy and data sources}

A comprehensive search strategy was developed to find studies reporting data on women with ATTR-CM in the published literature. Multiple search terms for transthyretin amyloidosis and variations of the wild-type and hereditary subtypes were used in combination with terms for cardiomyopathy and women using the Boolean operator "AND" (Supplementary Table 1). Searches were conducted for studies published in English through August 16, 2019, based on electronic searches of the following databases: MEDLINE ${ }^{\circledR}$, Embase $^{\circledR}$,
Cochrane Central Register of Controlled Trials, and Cochrane Database of Systematic Reviews. A manual cross-referencing search was also conducted of the PubMed ${ }^{\circledR}$ database. Reference lists of the published literature identified in the database searches, as well as relevant review articles, were manually searched to identify publications that may not have appeared in the original electronic searches. In addition, to capture the most recent and relevant studies on this topic that are not yet published, manual searches were conducted of proceedings from the following conferences: the European Society of Cardiology, Heart Failure Society of America, and International Society of Amyloidosis.

\section{Study screening, selection, and data extraction}

The flow of publications/studies through the search and screening process is summarized in Fig. 1. After removal of duplicate citations in the initial searches, publication titles and abstracts were assessed against inclusion/exclusion criteria in the first of 2 rounds of screening by 2 independent reviewers. In the second screening round, the reviewers examined complete texts of the publications for eligibility. If agreement on discrepancies between the 2 reviewers could not be reached, a third senior investigator reached a final decision. Data from the included publications were extracted by one reviewer and validated by the second reviewer for quality assurance, then reported in pre-specified data-extraction tables. Excluded studies were documented along with the reason for their exclusion.

Based on the PICOS (Population, Intervention, Comparison, Outcome, Study design) framework [22], study inclusion criteria encompassed the following: (i) original studies of adult women with ATTR-CM, including subpopulations of women with wild-type and hereditary disease subtypes, (ii) interventional or non-interventional studies with or without comparator, (iii) studies reporting sex-specific data (e.g., demographic characteristics, ATTR genotype, clinical measures, biomarkers, imaging, incidence, frequency, mortality, comorbidities, and hormonal status), and (iv) controlled clinical trials (randomized and non-randomized) and observational studies (prospective and retrospective). Diagnostic criteria used to identify patients with ATTR-CM were based primarily on recommendations of the 2019 Multi-societal Expert Consensus Committee (Supplementary Table 2) [23]. The hereditary subtype of ATTR-CM was confirmed via TTR genopositivity established by DNA analysis or mass spectrometry.

\section{Pooled analysis}

Findings from selected included studies were pooled to analyze the proportions of women and men who had wild-type ATTR-CM, hereditary ATTR-CM, and undefined ATTR-CM. 


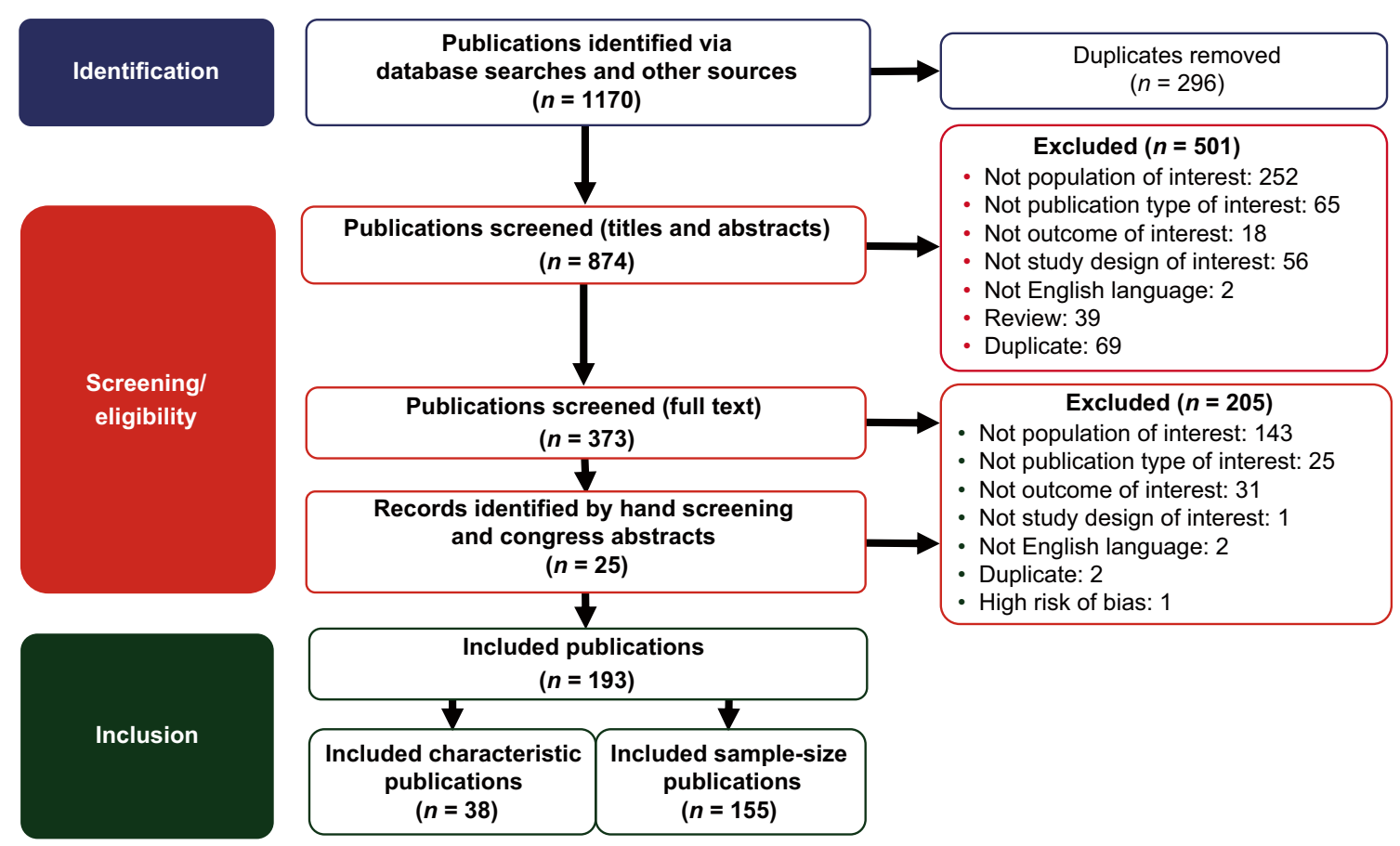

Fig. 1 Flow of publications/studies through the search and screening process

Studies that reported sample size were excluded from the pooled analysis if they were found to include data from convenient or pre-specified patient populations, or populations that overlapped with other included studies (e.g., publications from the same author/institution or registry/survey during a similar time frame). When studies overlapped, the publication with the largest reported patient population was retained.

\section{Study quality assessment}

The research quality of relevant case series and cohort studies identified in the searches (characteristic publications only) was critically appraised using the Joanna Briggs Institute Critical Appraisal Tool and the Newcastle-Ottawa scale, respectively (Supplementary Table 3 ). Congress abstracts were not assessed for quality. Studies that received a poor assessment on the risk of bias appraisal were excluded.

\section{Results}

\section{Literature search/screening}

Among 1170 total publications identified in the initial literature searches (Embase, $n=642$; MEDLINE, $n=417$; Cochrane, $n=111$ ), 193 publications met the final eligibility criteria, including 185 full-text publications and 8 congress abstracts (Fig. 1). A total of 155 publications provided information only on sample sizes for women and men with ATTR$\mathrm{CM}$, and 38 provided a description of ATTR-CM characteristics in patients of both sexes, as well as diagnostic techniques. Among the publications reporting sample sizes, 8 (5\%) were based on controlled studies (randomized, $n=5$; non-randomized, $n=3)$, and $147(95 \%)$ were based on observational studies (retrospective, $n=87$; prospective, $n=60$ ). The ATTR-CM subtype breakdown in these studies was wild-type ATTR-CM, 58 (36\%); hereditary ATTR-CM, 62 (40\%); and undefined ATTR-CM, 67 (43\%). (Some studies included multiple ATTR-CM subtypes.) Among the publications reporting disease characteristics, 30 (79\%) were based on case series and $8(21 \%)$ were based on cohort studies. Of these, the ATTR-CM subtype breakdown was wild-type ATTR-CM, 15 (39\%); hereditary ATTR-CM, 29 (76\%); and undefined ATTR-CM, 5 (13\%).

Findings from 69 selected studies (sample size studies, $n=$ 52; disease characteristics studies, $n=17$ ) were pooled to assess ATTR-CM epidemiology. Twenty-five of the pooled studies (36\%) included patients with wild-type ATTR-CM, $25(36 \%)$ included patients with hereditary ATTR-CM, and $30(43 \%)$ included patients with undefined ATTR-CM. (As above, some studies included multiple ATTR-CM subtypes.) Studies of wild-type, hereditary, and undefined ATTR-CM included 2027, 1279, and 1363 individuals, respectively.

\section{Frequency of wild-type and hereditary ATTR-CM}

Across studies included in the pooled analysis, 791 of 4669 (17\%) patients with ATTR-CM were women. In the studies of wild-type, hereditary, and undefined ATTR-CM, 174 (9\%), $366(29 \%)$, and 251 (18\%) patients were women, respectively. 
When the proportions of women were analyzed in ranges (i.e., $\leq 10 \%,>10-30 \%$, and $>30 \%$ ), some differences between studies were evident (Fig. 2). For studies of wild-type and undefined ATTR-CM, the majority-92\% (23/25) and 77\% (23/30), respectively - reported that less than $30 \%$ of patients were women. In contrast, for studies of hereditary ATTR-CM, the majority-56\% (14/25) - reported that more than $30 \%$ of patients were women.

\section{Sex-related differences in demographic and clinical characteristics}

Overall, no marked numerical differences between women and men with ATTR-CM in age or ethnicity were seen across studies that reported these characteristics (Table 1; Supplementary Tables 4-6) [24-40]. However, some anatomical differences in cardiac structure were identified (Fig. 3ac); namely, women had numerically lower values for interventricular septal thickness, posterior wall thickness, and LV diastolic diameter compared with men in studies of wild-type $[10,31,39]$, hereditary [29, 41-43], and undefined ATTRCM $[24,26]$. In addition, LV ejection fraction was numerically higher in women than men in several studies across ATTRCM genotypes (Fig. 3d) [10, 31, 41, 44]. In studies that reported on survival and mortality $[6,10,24,35,37,38,40,41$, 45-47], these outcomes did not appear to be different between women and men.

\section{Screening/diagnostic techniques in ATTR-CM}

A number of tests may be conducted in patients with suspected ATTR-CM to examine the risk that the condition is present. In the studies included in this review, echocardiography was the most frequently reported test, conducted in 14 of $38(37 \%)$ studies $[6,10,26,31-33,37,39,41,42,44$, 48-50] (Fig. 4). Clinical symptoms (5 [13\%]), magnetic

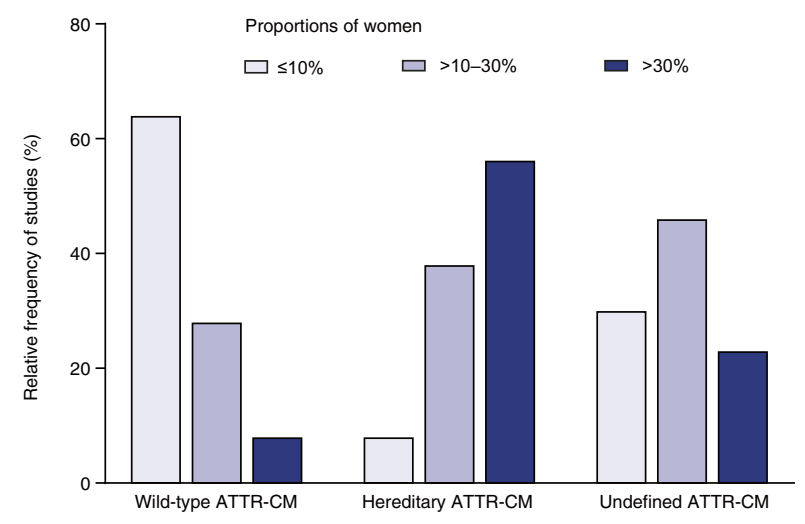

No. of studies

25 resonance imaging (MRI; 4 [11\%]), and Western blot assay (4 [11\%]) were other features or techniques used to screen for ATTR-CM in similar proportions of studies.

Multiple approaches can be taken to establish a diagnosis of ATTR-CM, including endomyocardial or extracardiac biopsy, mass spectrometry, and nuclear scintigraphy; in addition, DNA genotyping can be used to confirm the presence or absence of a TTR gene mutation after the diagnosis is established [18]. The number of published studies including these diagnostic techniques, alone or in combination, is shown in Fig. 4. The most common were cardiac biopsy [6, 10, 24-26, 28, 31-39, 41, 43, 44, 46, 47, 49-54], DNA genotyping $[6,10,25,27-30,33,37,40-45,47,48,51-53,55-58]$, and extracardiac biopsy, performed in $26(68 \%), 24(63 \%)$, and $19(50 \%)$ studies, respectively. Biopsy was not performed in $6(16 \%)$ studies [27, 29, 30, 40, 55, 57], but DNA genotyping was conducted in all 6 of these studies and nuclear scintigraphy in 2 of the 6 studies. Cardiac and extracardiac biopsies were conducted together in 14 (37\%) $[6,10,26,28,33$, $39,41,44,46,51-54]$ studies, and cardiac biopsy and DNA genotyping were conducted together in $13(34 \%)$ studies [6, $10,25,28,33,37,41,43,44,47,51-53]$.

\section{Discussion}

Based on a pooled analysis of 69 studies, among 4669 patients with ATTR-CM, we found that $17 \%$ were women and $83 \%$ were men. The lowest proportion of women $(9 \%)$ was observed in studies of wild-type ATTR-CM, whereas the highest (29\%) was observed in studies of hereditary ATTR-CM. These findings are consistent with previous reports that ATTR-CM is a condition predominantly identified in men $[6,39]$, especially for the wild-type versus the hereditary subtype [6-8].

The research reviewed in the current publication does not elucidate the potential underlying mechanisms for the predominance of this condition in men or the higher proportion of women presenting with hereditary versus wild-type ATTR$\mathrm{CM}$, nor does it capture potential bias in reporting. Sex hormones and sex chromosomes have been shown to account for sex differences in cardiovascular disease [59, 60], and findings from several studies suggest that these factors may also help explain discrepancies in the prevalence and onset of ATTR-CM between men and women [41, 54, 61-63]. In a study of differences in penetrance of hereditary amyloidosis (i.e., the Val30Met ATTR pathogenic variant), Hellman et al. observed that penetrance of the trait was significantly higher when inherited from the mother than from the father [62]. In an earlier Swedish genealogical study, the age of onset was shown to be significantly higher when the mutation was inherited from the father, and anticipation (i.e., higher penetrance in younger generations) was greater in descendants of 
Table 1 Demographic and clinical characteristics by genotype, study type, and patient sex

\begin{tabular}{|c|c|c|c|c|c|c|c|c|c|c|c|c|}
\hline \multirow[t]{3}{*}{ Characteristic } & \multicolumn{6}{|c|}{ Wild-type ATTR-CMa } & \multicolumn{6}{|c|}{ Hereditary ATTR-CM ${ }^{\mathrm{b}}$} \\
\hline & \multicolumn{3}{|c|}{ Case series $(n=7)$} & \multicolumn{3}{|c|}{ Cohorts $(n=5)$} & \multicolumn{3}{|c|}{ Case series $(n=22)$} & \multicolumn{3}{|c|}{ Cohorts $(n=4)$} \\
\hline & $\begin{array}{l}\text { Studies } \\
n(\%)\end{array}$ & Men & Women & $\begin{array}{l}\text { Studies } \\
n(\%)\end{array}$ & Men & Women & $\begin{array}{l}\text { Studies } \\
n(\%)\end{array}$ & Men & Women & $\begin{array}{l}\text { Studies } \\
n(\%)\end{array}$ & Men & Women \\
\hline Sample size, $n$ & $7(100)$ & NR-9 & $1-5$ & $5(100)$ & $5-668$ & $1-43$ & $22(100)$ & $1-45$ & $1-21$ & $4(100)$ & $37-227$ & $12-96$ \\
\hline Sample size, \% & $7(100)$ & NR-89 & $11-100$ & $5(100)$ & $82-93$ & $6-18.5$ & $22(100)$ & $1-91$ & $9-100$ & $4(100)$ & $67-80$ & $20-33$ \\
\hline \multicolumn{13}{|c|}{ Age, years } \\
\hline $\begin{array}{l}\text { Baseline, } \\
\text { range }\end{array}$ & $7(100)$ & $66-98$ & $60-108$ & $1(20)$ & $70-92$ & 79 & $15(68)$ & $35-93$ & $42-91$ & $1(25)$ & $31-79$ & $30-86$ \\
\hline $\begin{array}{l}\text { Onset, } \\
\text { range/- } \\
\text { mean (SD) }\end{array}$ & 0 & NR & NR & $1(20)$ & $76.1(7.9)$ & $82.3 *(6.6)$ & $9(41)$ & $22-80$ & $24-78$ & 0 & NR & NR \\
\hline $\begin{array}{l}\text { Diagnosis, } \\
\text { mean (SD) }\end{array}$ & 0 & NR & NR & $1(20)$ & $77.4(7.8)$ & $83.9 *(6.2)$ & 0 & NR & NR & $1(25)$ & 49.6 & 47.4 \\
\hline \multicolumn{13}{|c|}{ TTR genotype, $\%$} \\
\hline Val30Met & NR & & & & & & $11(50)$ & $9-100$ & $33-100$ & $2(50)$ & $32-100$ & $20-100$ \\
\hline Val122Ile & - & & & & & & $4(18)$ & $7-75$ & $50-100$ & $1(25)$ & 71 & 29 \\
\hline \multicolumn{13}{|l|}{ Region, $n(\%)$} \\
\hline Europe & $2(29)$ & NR & & $4(80)$ & NR & & $13(59)$ & NR & & $4(100)$ & NR & \\
\hline $\begin{array}{l}\text { North } \\
\text { America }\end{array}$ & $4(57)$ & - & & 0 & - & & $2(9)$ & - & & - & - & \\
\hline Asia & $1(14)$ & - & & $1(20)$ & - & & $8(36)$ & - & & - & - & \\
\hline Multinational & - & - & & - & - & & $1(5)$ & - & & - & - & \\
\hline \multicolumn{13}{|c|}{ Race/ethnicity, \% } \\
\hline White & $1(14)$ & 67 & 100 & 0 & NR & NR & $3(14)$ & $45-100$ & $50-100$ & 0 & NR & \\
\hline Black & $2(29)$ & $33-100$ & $0-100$ & 0 & NR & NR & $4(18)$ & $33-100$ & $50-100$ & 0 & NR & \\
\hline Asian & $1(14)$ & 100 & 100 & $1(20)$ & 100 & 100 & $8(36)$ & 100 & 100 & 0 & NR & \\
\hline $\begin{array}{l}\text { Carpal tunnel } \\
\text { syndrome, } \\
\%\end{array}$ & $2(29)$ & NR & $50-100$ & $2(40)$ & $35-49$ & $25-43$ & $5(23)$ & $11-100$ & $0-100$ & 0 & NR & \\
\hline \multicolumn{13}{|c|}{ NT-proBNP, pg/mL } \\
\hline Range & $2(29)$ & $51-458$ & $431-3248$ & $1(20)$ & $1576-8357$ & $1720-11,171$ & $7(32)$ & $134-14,056$ & $220-9646$ & 0 & NR & \\
\hline Mean (SD) & 0 & NR & NR & $1(20)$ & 3514 (4988) & $4232(7509)$ & - & - & - & - & - & \\
\hline $\begin{array}{l}\text { Aortic } \\
\quad \text { stenosis, \% }\end{array}$ & $2(29)$ & 100 & $40-100$ & $1(20)$ & 3 & 0 & $1(5)$ & NR & 100 & 0 & NR & \\
\hline \multicolumn{13}{|c|}{ Interventricular septal thickness, mm } \\
\hline Range & 1 & $(13-16)$ & $(8-11)$ & $2(40)$ & $18-19$ & $16-19$ & $10(45)$ & $11-27$ & $7-26$ & $1(25)$ & $10-20$ & $10-16$ \\
\hline Mean (SD) & - & - & - & - & - & - & $1(5)$ & NR & $16(1)$ & $1(25)$ & - & $11.6(2.9)$ \\
\hline \multicolumn{13}{|c|}{ Posterior wall thickness, mm } \\
\hline Range & 1 & $(13-16)$ & $(12-15)$ & $2(40)$ & $16-16.5$ & $14-15.6$ & $6(23)$ & $11-25$ & $10-24$ & $1(25)$ & $10-13$ & $9-10$ \\
\hline Mean (SD) & - & - & - & - & - & - & - & - & - & $1(25)$ & $13.3(3.6)$ & $11.4(2.5)$ \\
\hline $\begin{array}{l}\text { LV diastolic } \\
\text { diameter, } \\
\mathrm{mm}\end{array}$ & 0 & NR & & $1(20)$ & 46 & 41 & $3(14)$ & $42-54$ & $31-54$ & $1(25)$ & $42-52$ & $39-50$ \\
\hline \multicolumn{13}{|l|}{ LV mass, $\mathrm{g}$} \\
\hline Mean (SD) & 0 & NR & & $1(20)$ & $513(162)$ & $281(1)$ & 0 & NR & & - & 90-209 & $81-152$ \\
\hline \multicolumn{13}{|c|}{ Ejection fraction, $\%$} \\
\hline Range & $4(57)$ & $50-80$ & $57-77$ & $2(40)$ & $45-51$ & $51-59$ & $5(23)$ & $25-73$ & $30-61$ & $1(25)$ & $58-71$ & $57-74$ \\
\hline Mean (SD) & - & - & - & - & - & - & $1(5)$ & NR & $50(1)$ & $1(25)$ & $58.6(10.2)$ & $66(12.4)$ \\
\hline $\begin{array}{l}\text { Atrial } \\
\text { fibrillation, } \\
\%\end{array}$ & $2(33)$ & $25-33$ & $33-40$ & $2(40)$ & $56-61$ & $47-55$ & $2(9)$ & $7-33$ & $33-100$ & 0 & NR & \\
\hline \multirow[t]{3}{*}{ Characteristic } & Studies o & f undefine & ed ATTR-C & $\mathbf{M}^{\mathbf{c}}$ & & & & & & & & \\
\hline & Case seri & es $(n=3)$ & & & & Cohorts $(n=1$ & & & & & & \\
\hline & Studies $n$ & $(\%)$ & Men & & Women & Studies $n(\%)$ & & & Men & & Women & \\
\hline Sample size, $n$ & $3(100)$ & & $1-15$ & & $2-10$ & $1(100)$ & & & 45 & & 6 & \\
\hline Sample size, $\%$ & $3(100)$ & & $33-60$ & & $40-67$ & $1(100)$ & & & 88 & & 12 & \\
\hline Age, years & & & & & & & & & & & & \\
\hline $\begin{array}{l}\text { Baseline, } \\
\text { range }\end{array}$ & $3(100)$ & & $59-97$ & & $64-91$ & 0 & & & NR & & & \\
\hline Region, $n(\%)$ & & & & & & & & & & & & \\
\hline Europe & $1(33)$ & & - & & - & $1(100)$ & & & - & & & \\
\hline $\begin{array}{l}\text { North } \\
\text { America }\end{array}$ & $2(67)$ & & - & & - & 0 & & & NR & & & \\
\hline Race/ethnicity, & & & & & & & & & & & & \\
\hline Black & $1(33)$ & & 100 & & 100 & 0 & & & NR & & & \\
\hline & $1(33)$ & & 38 & & 0 & 0 & & & NR & & & \\
\hline
\end{tabular}


Table 1 (continued)

\begin{tabular}{|c|c|c|c|c|c|c|}
\hline \multicolumn{7}{|l|}{$\begin{array}{l}\text { Carpal tunnel } \\
\text { syndrome, } \\
\%\end{array}$} \\
\hline \multicolumn{7}{|c|}{ NT-proBNP, pg/mL } \\
\hline Range & $1(33)$ & (124-7846) & (959-2799) & 0 & \multicolumn{2}{|l|}{ NR } \\
\hline $\begin{array}{l}\text { Aortic } \\
\quad \text { stenosis, \% }\end{array}$ & $1(33)$ & 100 & 50 & 0 & \multicolumn{2}{|l|}{ NR } \\
\hline \multicolumn{7}{|c|}{ Interventricular septal thickness, mm } \\
\hline Range & $1(33)$ & $22^{\mathrm{d}}$ & (13-14) & 0 & \multicolumn{2}{|l|}{ NR } \\
\hline Mean (SD) & $1(33)$ & $16(1.5)$ & $17.25(2.1)$ & 0 & \multicolumn{2}{|l|}{ NR } \\
\hline \multicolumn{7}{|c|}{ Posterior wall thickness, mm } \\
\hline Mean (SD) & $1(33)$ & $16(1.7)$ & $16.5(1.7)$ & 0 & \multicolumn{2}{|l|}{ NR } \\
\hline \multicolumn{7}{|c|}{ LV diastolic diameter, mm } \\
\hline Mean (SD) & $1(33)$ & $53.5(8.8)$ & $46(9.5)$ & 0 & \multicolumn{2}{|l|}{ NR } \\
\hline LV mass, $\mathrm{g}$ & 0 & NR & & $1(100)$ & $106-140$ & $95-116$ \\
\hline \multicolumn{7}{|c|}{ Ejection fraction, $\%$} \\
\hline Range & $1(33)$ & $55^{\mathrm{d}}$ & $56-69$ & 0 & NR & NR \\
\hline Mean (SD) & 0 & NR & NR & $1(100)$ & $55(12)$ & $62(14)$ \\
\hline $\begin{array}{l}\text { Atrial } \\
\text { fibrillation, } \\
\%\end{array}$ & $2(67)$ & $0-7$ & $10-33$ & 0 & \multicolumn{2}{|l|}{ NR } \\
\hline
\end{tabular}

ATTR-CM transthyretin amyloid cardiomyopathy, $L V$ left ventricular, $N R$ not reported, $N T$-proBNP N-terminal pro-B-type natriuretic peptide, $S D$ standard deviation

$* P<0.01$

${ }^{a}$ Three studies were excluded because they did not include data for women with wild-type ATTR-CM

${ }^{\mathrm{b}}$ Three studies were excluded because they included only women or only men with hereditary ATTR-CM

${ }^{\mathrm{c}}$ One study was excluded because it did not include data for women with ATTR-CM

${ }^{\mathrm{d}}$ Based on limited data $(n=1)$

mothers with the disease [63]. It is also possible that genetic counseling and mutations identified within families with a history of hereditary disease improve detection of this genotype in women, particularly as women may be more inclined to seek the help of healthcare providers [64-66]. These sexbiasing factors are complex, and many other factors, including age and ascertainment bias, are also expected to play a role.

The large degree of heterogeneity between studies reporting characteristics of ATTR-CM prevented metaanalysis of the data, but we observed trends suggestive of potential sex-based differences. Across studies, lower interventricular septal and posterior wall thickness and higher LV ejection fractions were reported in women compared with men. These trends are consistent with reported measurements for normal and abnormal hearts [67]. A suggested cut-off criterion for the diagnosis of ATTR-CM is an LV wall thickness $>12 \mathrm{~mm}$ in both sexes [23]. Given that both normal and abnormal cardiac anatomy is smaller in women than men, which our findings suggest is also the case for women and men with ATTR-CM, women with ATTR-CM could be at risk for potential underdiagnosis because they are less likely to meet the diagnostic wallthickness threshold. Further research is warranted to determine whether use of lower cut-off values or cardiac dimensions indexed by body size for women will affect rates of suspicion and ultimately diagnosis of ATTR-CM in women.
Various approaches may be used to help raise suspicion of ATTR-CM and facilitate earlier identification of the disease, including echocardiogram (ECHO), electrocardiogram (ECG), cardiac magnetic resonance imaging (cMRI), and biomarker clues [18, 23, 68]. ECHO was the most frequently reported test conducted in the studies in this review, reflecting the prominent role this test has traditionally played in the evaluation of cardiac structure and function in patients with troubling heart symptoms. However, the limited sensitivity and specificity of ECHO for ATTR-CM may contribute to missed or late diagnoses of amyloidosis. Although ECG may be useful in identifying ATTR-CM, none of the studies reported use of this diagnostic technique. Similarly, no studies used the cardiac biomarkers N-terminal pro-B-type natriuretic peptide or troponin to confirm the diagnosis of ATTR-CM, although these markers reportedly predict mortality in patients with wild-type ATTR-CM and are thus used for risk stratification [69]. Therefore, our findings suggest that additional guidance on the assessment of patients with suspected ATTR-CM is needed to help raise awareness among clinicians and encourage earlier diagnosis.

In recently published multi-societal expert consensus recommendations, several diagnostic criteria were proposed for ATTR-CM, primarily based on endomyocardial biopsy, extracardiac biopsy, or scintigraphy, as were guidelines for the appropriate use of multimodality imaging [18]. The majority of studies included in the current systematic review were 


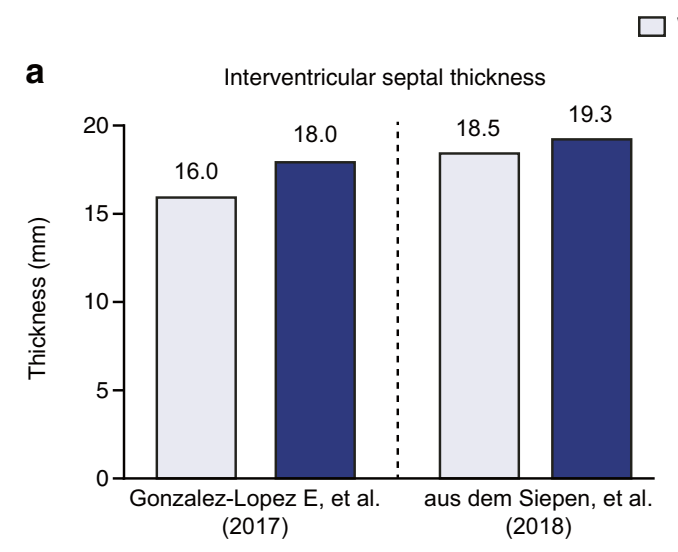

Women

b Posterior wall thickness
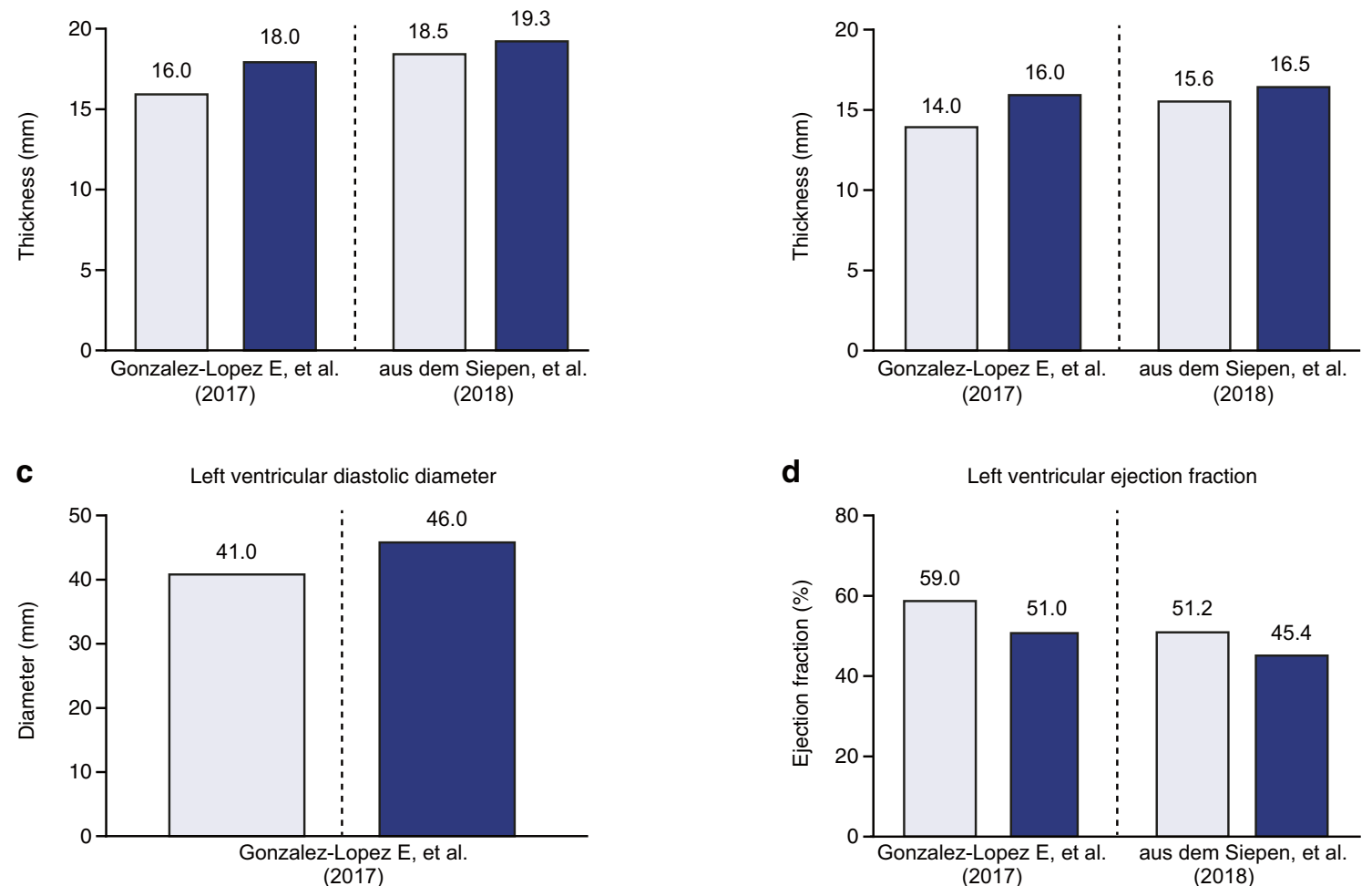

Fig. 3 Echocardiographic measurements for women versus men with wild-type ATTR-CM in cohort studies. a Interventricular septal thickness. b Posterior wall thickness. c LV diastolic diameter. d LV ejection fraction [10, 31]. ATTR-CM transthyretin amyloid cardiomyopathy, $L V$ left ventricular

designed and conducted prior to publication of these recommendations/guidelines (in 2019), but the study findings related to diagnostic testing are nonetheless of interest. The use of non-invasive scintigraphy was not commonly reported in this SLR, but substantial research supports its utilization. In a large, multicenter study in $>1000$ patients with biopsyproven cardiac amyloidosis, Gillmore et al. demonstrated that positive nuclear cardiac scintigraphy was $100 \%$ specific for ATTR-CM when light-chain amyloidosis (AL) was concurrently ruled out in patients with a visual myocardial uptake

a

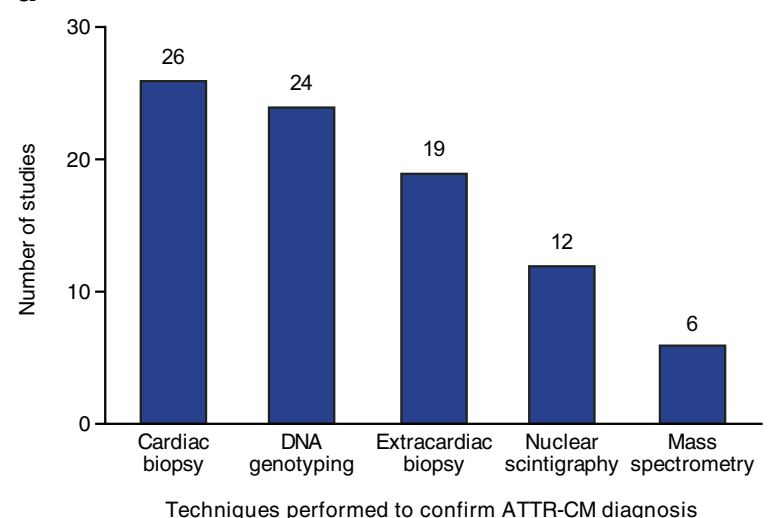

grading of 2 and 3 [19]. The range of diagnostic tests reported in the studies included in our review (i.e., cardiac and extracardiac biopsy, mass spectrometry, DNA genotyping, and scintigraphy) does not reveal a breach between the consensus ATTR-CM diagnostic recommendations and practice in clinical research. However, we found some evidence of inconsistencies in the approach: for example, cardiac and extracardiac biopsies were conducted together in 14 (37\%) studies, and cardiac biopsy and DNA genotyping were conducted together in 13 (34\%) studies. These findings indicate

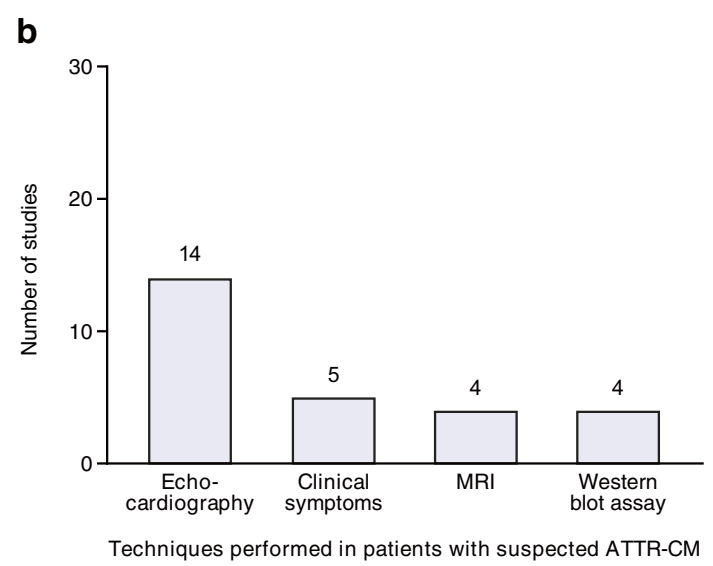

Fig. 4 Techniques used a to confirm a diagnosis of ATTR-CM or $\mathbf{b}$ to investigate suspected ATTR-CM $(n=38)$. ATTR-CM transthyretin amyloid cardiomyopathy, MRI magnetic resonance imaging 
that broader education on the consensus recommendations is needed to encourage more uniform application of assessment and diagnostic criteria.

A number of limitations should be considered when assessing the findings of this SLR, including the small sample sizes of the studies, particularly for women, and the limited data available, particularly in cohort studies. The majority of these data were derived from case series rather than cohort studies, impeding direct comparison of data between women and men. Other limitations include heterogeneity in the stage at which patients were recruited in the studies (i.e., previously diagnosed patients, patients with suspected ATTR-CM, and patients pre-selected for another condition), heterogeneity in the statistical reporting of data (e.g., means vs. medians), and heterogeneity in time frames and duration of follow-up (i.e., from onset or time of biopsy or pre- and post-liver transplant to variable follow-up visit or death). Finally, the criteria used to confirm the presence of ATTR-CM (e.g., interventricular septal thickness $>12 \mathrm{~mm}$, positive biopsy or scintigraphy) may have biased patient selection and may have been inaccurate for identifying women with ATTR-CM.

The results of this literature review indicate that ATTR-CM is a condition predominantly reported in men compared with women. The disparity between sexes in ATTR-CM frequency may be explained by several factors, including potential cardioprotective effects of estrogen, smaller heart structures in women that do not meet diagnostic thresholds for ATTR$\mathrm{CM}$, and a lack of awareness of red flags for ATTR-CM in women compared with men. Interpretation of the literature was limited by the heterogeneous nature of the studies included and the small patient populations involved, but our findings raise important questions and reinforce the need for additional investigation into sex-related differences in ATTR-CM.

Acknowledgments The authors would like to thank Selma Mohammed, MD, of the Division of Cardiology, Creighton University, Omaha, NE, for her contributions to the development of the systematic literature review and the valuable comments on drafts of this manuscript.

Funding information The systematic literature review to support this manuscript was sponsored by Pfizer.

\section{Compliance with ethical standards}

Conflicts of interest Drs. Bruno, Castaño, and Burton are full-time employees of Pfizer and may hold Pfizer stock and/or stock options. Dr. Grodin has received funding as a consultant for Pfizer and Eidos.

Medical writing support for this article was provided by Donna McGuire of Engage Scientific Solutions and was funded by Pfizer. Sara Lucas, $\mathrm{PhD}$, and Catherine Rolland, $\mathrm{PhD}$, are employees of Envision Pharma Group and paid consultants to Pfizer in connection with the development of the SLR report that forms the basis of this manuscript. They were not compensated for their role in the review of this manuscript.

Ethics approval and consent to participate Not applicable.
Consent for publication All the authors provided consent for the publication of this article.

Open Access This article is licensed under a Creative Commons Attribution 4.0 International License, which permits use, sharing, adaptation, distribution and reproduction in any medium or format, as long as you give appropriate credit to the original author(s) and the source, provide a link to the Creative Commons licence, and indicate if changes were made. The images or other third party material in this article are included in the article's Creative Commons licence, unless indicated otherwise in a credit line to the material. If material is not included in the article's Creative Commons licence and your intended use is not permitted by statutory regulation or exceeds the permitted use, you will need to obtain permission directly from the copyright holder. To view a copy of this licence, visit http://creativecommons.org/licenses/by/4.0/.

\section{References}

1. Rapezzi C, Quarta CC, Riva L, Longhi S, Gallelli I, Lorenzini M, Ciliberti P, Biagini E, Salvi F, Branzi A (2010) Transthyretinrelated amyloidoses and the heart: a clinical overview. Nat Rev Cardiol 7(7):398-408. https://doi.org/10.1038/nrcardio.2010.67

2. Donnelly JP, Hanna M (2017) Cardiac amyloidosis: an update on diagnosis and treatment. Cleve Clin J Med 84(12 Suppl 3):12-26. https://doi.org/10.3949/ccjm.84.s3.02

3. Gillmore JD, Damy T, Fontana M, Hutchinson M, Lachmann HJ, Martinez-Naharro A, Quarta CC, Rezk T, Whelan CJ, GonzalezLopez E, Lane T, Gilbertson JA, Rowczenio D, Petrie A, Hawkins PN (2018) A new staging system for cardiac transthyretin amyloidosis. Eur Heart J 39(30):2799-2806

4. Jacobson DR, Alexander AA, Tagoe C, Buxbaum JN (2015) Prevalence of the amyloidogenic transthyretin (TTR) V122I allele in 14333 African-Americans. Amyloid 22(3):171-174. https://doi. org/10.3109/13506129.2015.1051219

5. González-López E, Gallego-Delgado M, Guzzo-Merello G, de Haro-del Moral FJ, Cobo-Marcos M, Robles C, Bornstein B, Salas C, Lara-Pezzi E, Alonso-Pulpon L, Garcia-Pavia P (2015) Wild-type transthyretin amyloidosis as a cause of heart failure with preserved ejection fraction. Eur Heart J 36(38):2585-2594. https:// doi.org/10.1093/eurheartj/ehv338

6. Lane T, Fontana M, Martinez-Naharro A, Quarta CC, Whelan CJ, Petrie A, Rowczenio DM, Gilbertson JA, Hutt DF, Rezk T, Strehina SG, Caringal-Galima J, Manwani R, Sharpley FA, Wechalekar AD, Lachmann HJ, Mahmood S, Sachchithanantham S, Drage EPS, Jenner HD, McDonald R, Bertolli O, Calleja A, Hawkins PN, Gillmore JD (2019) Natural history, quality of life, and outcome in cardiac transthyretin amyloidosis. Circulation 140(1):16-26

7. Yamamoto H, Yokochi T (2019) Transthyretin cardiac amyloidosis: an update on diagnosis and treatment. ESC Heart Fail 6(6): 1128-1139. https://doi.org/10.1002/ehf2.12518

8. Maurer MS, Hanna M, Grogan M, Dispenzieri A, Witteles R, Drachman B, Judge DP, Lenihan DJ, Gottlieb SS, Shah SJ, Steidley DE, Ventura H, Murali S, Silver MA, Jacoby D, Fedson S, Hummel SL, Kristen AV, Damy T, Plante-Bordeneuve V, Coelho T, Mundayat R, Suhr OB, Waddington Cruz M, Rapezzi C (2016) Genotype and phenotype of transthyretin cardiac amyloidosis: THAOS (Transthyretin Amyloid Outcome Survey). J Am Coll Cardiol 68(2):161-172. https://doi.org/10.1016/j.jacc. 2016.03.596

9. Pinney JH, Whelan CJ, Petrie A, Dungu J, Banypersad SM, Sattianayagam P, Wechalekar A, Gibbs SDJ, Venner CP, Wassef N, McCarthy CA, Gilbertson JA, Rowczenio D, Hawkins PN, 
Gillmore JD, Lachmann HJ (2013) Senile systemic amyloidosis: clinical features at presentation and outcome. J Am Heart Assoc 2(2):e000098

10. Gonzalez-Lopez E, Gagliardi C, Dominguez F, Quarta CC, De Haro-Del Moral FJ, Milandri A, Salas C, Cinelli M, CoboMarcos M, Lorenzini M, Lara-Pezzi E, Foffi S, Alonso-Pulpon L, Rapezzi C, Garcia-Pavia P (2017) Clinical characteristics of wildtype transthyretin cardiac amyloidosis: disproving myths. Eur Heart J 38(24):1895-1904

11. Connors LH, Sam F, Skinner M, Salinaro F, Sun F, Ruberg FL, Berk JL, Seldin DC (2016) Heart failure resulting from age-related cardiac amyloid disease associated with wild-type transthyretin: a prospective, observational cohort study. Circulation 133(3):282290. https://doi.org/10.1161/circulationaha.115.018852

12. Winburn I, Ishii T, Sumikawa T, Togo K, Yasunaga H (2019) Estimating the prevalence of transthyretin amyloid cardiomyopathy in a large in-hospital database in Japan. Cardiol Ther 8:297-316. https://doi.org/10.1007/s40119-019-0142-5

13. Witteles RM, Bokhari S, Damy T, Elliott PM, Falk RH, Fine NM, Gospodinova M, Obici L, Rapezzi C, Garcia-Pavia P (2019) Screening for transthyretin amyloid cardiomyopathy in everyday practice. JACC Heart Fail 7(8):709-716. https://doi.org/10.1016/j. jchf.2019.04.010

14. Alnylam (2019) APOLLO-B: a study to evaluate patisiran in participants with transthyretin amyloidosis with cardiomyopathy (ATTR amyloidosis with cardiomyopathy) (NCT03997383) (2019) https://clinicaltrials.gov/ct2/show/NCT03997383. Accessed 31 October 2019

15. Judge DP, Heitner SB, Falk RH, Maurer MS, Shah SJ, Witteles RM, Grogan M, Selby VN, Jacoby D, Hanna M, Nativi-Nicolau J, Patel J, Rao S, Sinha U, Turtle CW, Fox JC (2019) Transthyretin stabilization by AG10 in symptomatic transthyretin amyloid cardiomyopathy. J Am Coll Cardiol 74(3):285-295. https://doi.org/10. 1016/j.jacc.2019.03.012

16. Falk RH (2018) 24 month open label study of the tolerability and efficacy of inotersen in TTR amyloid cardiomyopathy patients (NCT03702829). https://clinicaltrials.gov/ct2/show/ NCT03702829. Accessed 31 October 2019

17. Pfizer (2019) US FDA approves Vyndaqel ${ }^{\circledR}$ and Vyndamax ${ }^{\mathrm{TM}}$ for use in patients with transthyretin amyloid cardiomyopathy, a rare and fatal disease (press release). https://www.pfizer.com/news/ press-release/press-release-detail/u_s_fda_approves_vyndaqel_ and_vyndamax_for_use_in_patients_with_transthyretin_amyloid cardiomyopathy_a_rare_and_fatal_disease. Accessed 30 June 2019

18. Dorbala S, Ando $\bar{Y}$, Bokhari S, Dispenzieri A, Falk RH, Ferrari VA, Fontana M, Gheysens O, Gillmore JD, Glaudemans A, Hanna MA, Hazenberg BPC, Kristen AV, Kwong RY, Maurer MS, Merlini G, Miller EJ, Moon JC, Murthy VL, Quarta CC, Rapezzi C, Ruberg FL, Shah SJ, Slart R, Verberne HJ, Bourque JM (2019) ASNC/AHA/ASE/EANM/HFSA/ISA/SCMR/SNMMI Expert consensus recommendations for multimodality imaging in cardiac amyloidosis: part 1 of 2-evidence base and standardized methods of imaging. J Card Fail 25(11):e1-e39. https://doi.org/10.1016/j. cardfail.2019.08.001

19. Gillmore JD, Maurer MS, Falk RH, Merlini G, Damy T, Dispenzieri A, Wechalekar AD, Berk JL, Quarta CC, Grogan M, Lachmann HJ, Bokhari S, Castano A, Dorbala S, Johnson GB, Glaudemans AW, Rezk T, Fontana M, Palladini G, Milani P, Guidalotti PL, Flatman K, Lane T, Vonberg FW, Whelan CJ, Moon JC, Ruberg FL, Miller EJ, Hutt DF, Hazenberg BP, Rapezzi C, Hawkins PN (2016) Nonbiopsy diagnosis of cardiac transthyretin amyloidosis. Circulation 133(24):2404-2412. https:// doi.org/10.1161/circulationaha.116.021612

20. Shamseer L, Moher D, Clarke M, Ghersi D, Liberati A, Petticrew M, Shekelle P, Stewart LA (2015) Preferred reporting items for systematic review and meta-analysis protocols (PRISMA-P)
2015: elaboration and explanation. BMJ 350:g7647. https://doi. org/10.1136/bmj.g7647

21. National Institute for Health Research, PROSPERO International Prospective Register of Systematic Reviews (2019) A systematic review to identify and understand gender characteristics in men and women with transthyretin amyloidosis with cardiomyopathy (ATTR-CM). https://www.crd.york.ac.uk/PROSPERO/display_ record.php?RecordID=146995]. Accessed June 222020

22. Schardt C, Adams MB, Owens T, Keitz S, Fontelo P (2007) Utilization of the PICO framework to improve searching PubMed for clinical questions. BMC Med Inform Decis Mak 7:16. https:// doi.org/10.1186/1472-6947-7-16

23. Dorbala S, Ando Y, Bokhari S, Dispenzieri A, Falk RH, Ferrari VA, Fontana M, Gheysens O, Gillmore JD, Glaudemans A, Hanna MA, Hazenberg BPC, Kristen AV, Kwong RY, Maurer MS, Merlini G, Miller EJ, Moon JC, Murthy VL, Quarta CC, Rapezzi C, Ruberg FL, Shah SJ, Slart R, Verberne HJ, Bourque JM (2019) ASNC/AHA/ASE/EANM/HFSA/ISA/SCMR/SNMMI Expert consensus recommendations for multimodality imaging in cardiac amyloidosis: part 2 of 2-diagnostic criteria and appropriate utilization. J Card Fail 25(11):854-865. https://doi.org/10.1016/j.cardfail. 2019.08.002

24. Galat A, Guellich A, Bodez D, Slama M, Dijos M, Zeitoun DM, Milleron O, Attias D, Dubois-Rande JL, Mohty D, Audureau E, Teiger E, Rosso J, Monin JL, Damy T (2016) Aortic stenosis and transthyretin cardiac amyloidosis: the chicken or the egg? Eur Heart J 37(47):3525-3531

25. Jacobson DR, Pastore RD, Yaghoubian R, Kane I, Gallo G, Buck FS, Buxbaum JN (1997) Variant-sequence transthyretin (isoleucine 122 ) in late-onset cardiac amyloidosis in black Americans. N Engl J Med 336(7):466-473

26. Wizenberg TA, Muz J, Sohn YH, Samlowski W, Weissler AM (1982) Value of positive myocardial technetium-99mpyrophosphate scintigraphy in the noninvasive diagnosis of cardiac amyloidosis. Am Heart J 103(4 Pt 1):468-473. https://doi.org/10. 1016/0002-8703(82)90331-3

27. Choi K, Seok JM, Kim BJ, Choi YC, Shin HY, Sunwoo IN, Kim DS, Sung JJ, Lee GY, Jeon ES, Kim NH, Min JH, Oh J (2018) Characteristics of South Korean patients with hereditary transthyretin amyloidosis. J Clin Neurol (Korea) 14(4):537-541

28. Damy T, Costes B, Hagege AA, Donal E, Eicher JC, Slama M, Guellich A, Rappeneau S, Gueffet JP, Logeart D, PlantéBordeneuve V, Bouvaist H, Huttin O, Mulak G, Dubois-Rand JL, Goossens M, Canoui-Poitrine F, Buxbaum JN (2016) Prevalence and clinical phenotype of hereditary transthyretin amyloid cardiomyopathy in patients with increased left ventricular wall thickness. Eur Heart J 37(23):1826-1834

29. Morner S, Hellman U, Suhr OB, Kazzam E, Waldenstrom A (2005) Amyloid heart disease mimicking hypertrophic cardiomyopathy. J Intern Med 258(3):225-230

30. Vermeer AMC, Janssen A, Boorsma PC, Mannens M, Wilde AAM, Christiaans I (2017) Transthyretin amyloidosis: a phenocopy of hypertrophic cardiomyopathy. Amyloid 24(2):87-91. https://doi.org/10.1080/13506129.2017.1322573

31. aus dem Siepen F, Bauer R, Voss A, Hein S, Aurich M, Riffel J, Mereles D, Rocken C, Buss SJ, Katus HA, Kristen AV (2018) Predictors of survival stratification in patients with wild-type cardiac amyloidosis. Clin Res Cardiol 107(2):158-169

32. Kim D, Lee GY, Choi JO, Kim K, Kim SJ, Jeon ES (2019) Associations of electrocardiographic parameters with left ventricular longitudinal strain and prognosis in cardiac light chain amyloidosis. Sci Rep 9(1):7746

33. Rapezzi C, Merlini G, Quarta CC, Riva L, Longhi S, Leone O, Salvi F, Ciliberti P, Pastorelli F, Biagini E, Coccolo F, Cooke RM, Bacchi-Reggiani L, Sangiorgi D, Ferlini A, Cavo M, Zamagni E, Fonte ML, Palladini G, Salinaro F, Musca F, Obici L, Branzi A, 
Perlini S (2009) Systemic cardiac amyloidoses: disease profiles and clinical courses of the 3 main types. Circulation 120(13):12031212

34. Helder MRK, Schaff HV, Nishimura RA, Gersh BJ, Dearani JA, Ommen SR, Mereuta OM, Theis JD, Dogan A, Edwards WD (2014) Impact of incidental amyloidosis on the prognosis of patients with hypertrophic cardiomyopathy undergoing septal myectomy for left ventricular outflow tract obstruction. Am J Cardiol 114(9):1396-1399

35. Satoskar AA, Efebera Y, Hasan A, Brodsky S, Nadasdy G, Dogan A, Nadasdy T (2011) Strong transthyretin immunostaining: potential pitfall in cardiac amyloid typing. Am J Surg Pathol 35(11): 1685-1690. https://doi.org/10.1097/PAS.0b013e3182263d74

36. Sharma PP, Payvar S, Litovsky SH (2008) Histomorphometric analysis of intramyocardial vessels in primary and senile amyloidosis: epicardium versus endocardium. Cardiovasc Pathol 17(2):6571

37. Treibel TA, Fontana M, Gilbertson JA, Castelletti S, White SK, Scully PR, Roberts N, Hutt DF, Rowczenio DM, Whelan CJ, Ashworth MA, Gillmore JD, Hawkins PN, Moon JC (2016) Occult transthyretin cardiac amyloid in severe calcific aortic stenosis. Circ Cardiovasc Imaging 9(8):e005066

38. Xu B, Godoy Rivas C, Rodriguez ER, Tan C, Gillinov AM, Harb S, Jellis C, Griffin B (2019) Unrecognized cardiac amyloidosis at the time of mitral valve surgery: incidence and outcomes. Cardiology 142(4):253-258. https://doi.org/10.1159/000499933

39. Yamamoto Y, Onoguchi M, Haramoto M, Kodani N, Komatsu A, Kitagaki H, Tanabe K (2012) Novel method for quantitative evaluation of cardiac amyloidosis using ${ }^{201} \mathrm{Tl}-\mathrm{Cl}$ and ${ }^{99 \mathrm{~m}} \mathrm{Tc}-\mathrm{PYP}$ SPECT. Ann Nucl Med 26(8):634-643

40. Zegri-Reiriz I, de Haro-Del Moral FJ, Dominguez F, Salas C, de la Cuadra P, Plaza A, Krsnik I, Gonzalez-Lopez E, Garcia-Pavia P (2019) Prevalence of cardiac amyloidosis in patients with carpal tunnel syndrome. J Cardiovasc Transl Res 12(6):507-513. https:// doi.org/10.1007/s12265-019-09895-0

41. Rapezzi C, Riva L, Quarta CC, Perugini E, Salvi F, Longhi S, Ciliberti P, Pastorelli F, Biagini E, Leone O, Cooke RM, BacchiReggiani L, Ferlini A, Cavo M, Merlini G, Perlini S, Pasquali S, Branzi A (2008) Gender-related risk of myocardial involvement in systemic amyloidosis. Amyloid 15(1):40-48. https://doi.org/10. 1080/13506120701815373

42. Arvidsson S, Pilebro B, Westermark P, Lindqvist P, Suhr OB (2015) Amyloid cardiomyopathy in hereditary transthyretin V30M amyloidosis - impact of sex and amyloid fibril composition. PLoS One 10(11):e0143456. https://doi.org/10.1371/journal.pone. 0143456

43. Nelson WW, Choi JC, Vanderpoel J, Damaraju CV, Wildgoose P, Fields LE, Schein JR (2013) Impact of co-morbidities and patient characteristics on international normalized ratio control over time in patients with nonvalvular atrial fibrillation. Am J Cardiol 112(4): 509-512

44. Dungu JN, Valencia O, Pinney JH, Gibbs SD, Rowczenio D, Gilbertson JA, Lachmann HJ, Wechalekar A, Gillmore JD, Whelan CJ, Hawkins PN, Anderson LJ (2014) CMR-based differentiation of AL and ATTR cardiac amyloidosis. JACC Cardiovasc Imaging 7(2):133-142. https://doi.org/10.1016/j.jcmg.2013.08.015

45. Gustafsson $S$, Ihse E, Henein MY, Westermark P, Lindqvist $P$, Suhr OB (2012) Amyloid fibril composition as a predictor of development of cardiomyopathy after liver transplantation for hereditary transthyretin amyloidosis. Transplantation 93(10):1017-1023

46. Oshima T, Kawahara S, Ueda M, Kawakami Y, Tanaka R, Okazaki T, Misumi Y, Obayashi K, Yamashita T, Ohya Y, Ihse E, Shinriki $\mathrm{S}$, Tasaki M, Jono H, Asonuma K, Inomata Y, Westermark P, Ando Y (2014) Changes in pathological and biochemical findings of systemic tissue sites in familial amyloid polyneuropathy more than 10 years after liver transplantation. J Neurol Neurosurg Psychiatry 85(7):740-746

47. Yazaki M, Tokuda T, Nakamura A, Higashikata T, Koyama J, Higuchi K, Harihara Y, Baba S, Kametani F, Ikeda S (2000) Cardiac amyloid in patients with familial amyloid polyneuropathy consists of abundant wild-type transthyretin. Biochem Biophys Res Commun 274(3):702-706. https://doi.org/10.1006/bbrc.2000.3203

48. Haagsma EB, Van Gameren II, Bijzet J, Posthumus MD, Hazenberg BPC (2007) Familial amyloidotic polyneuropathy: long-term follow-up of abdominal fat tissue aspirate in patients with and without liver transplantation. Amyloid 14(3):221-226

49. Kero T, Sorensen J, Antoni G, Wilking H, Carlson K, Vedin O, Rosengren S, Wikstrom G, Lubberink M (2018) Quantification of (11)C-PIB kinetics in cardiac amyloidosis. J Nucl Cardiol 27:774 784. https://doi.org/10.1007/s12350-018-1349-x

50. Nelson LM, Gustafsson F, Gimsing P (2015) Characteristics and long-term outcome of patients with systemic immunoglobulin lightchain amyloidosis. Acta Haematol 133(4):336-346

51. Abulizi M, Cottereau AS, Guellich A, Vandeventer S, Galat A, Van Der Gucht A, Planté-Bordeneuve V, Dubois-Rande JL, Bodez D, Rosso J, Damy T, Itti E (2018) Early-phase myocardial uptake intensity of ${ }^{99 \mathrm{~m}} \mathrm{Tc}-\mathrm{HMDP}$ vs ${ }^{99 \mathrm{~m}} \mathrm{Tc}-\mathrm{DPD}$ in patients with hereditary transthyretin-related cardiac amyloidosis. J Nucl Cardiol 25(1): 217-222

52. Ihse E, Rapezzi C, Merlini G, Benson MD, Ando Y, Suhr OB, Ikeda SI, Lavatelli F, Obici L, Quarta CC, Leone O, Jono H, Ueda M, Lorenzini M, Liepnieks J, Ohshima T, Tasaki M, Yamashita T, Westermark P (2013) Amyloid fibrils containing fragmented ATTR may be the standard fibril composition in ATTR amyloidosis. Amyloid 20(3):142-150

53. Pilebro B, Arvidsson S, Lindqvist P, Sundstrom T, Westermark P, Antoni G, Suhr O, Sorensen J (2018) Positron emission tomography (PET) utilizing Pittsburgh compound B (PIB) for detection of amyloid heart deposits in hereditary transthyretin amyloidosis (ATTR). J Nucl Cardiol 25(1):240-248

54. Tasaki M, Ueda M, Obayashi K, Koike H, Kitagawa K, Ogi Y, Jono H, Su Y, Suenaga G, Oshima T, Misumi Y, Yoshida M, Yamashita T, Sobue G, Ando Y (2013) Effect of age and sex differences on wild-type transthyretin amyloid formation in familial amyloidotic polyneuropathy: a proteomic approach. Int J Cardiol 170(1):69-74

55. Di Bella G, Minutoli F, Mazzeo A, Vita G, Oreto G, Carerj S, Anfuso C, Russo M, Gaeta M (2010) MRI of cardiac involvement in transthyretin familial amyloid polyneuropathy. AJR Am J Roentgenol 195(6):W394-W399. https://doi.org/10.2214/AJR.09. 3721

56. Hattori T, Takei Y, Koyama J, Nakazato M, Ikeda S (2003) Clinical and pathological studies of cardiac amyloidosis in transthyretin type familial amyloid polyneuropathy. Amyloid 10(4):229-239

57. Koike H, Hashimoto R, Tomita M, Kawagashira Y, Ijijima M, Tanaka F, Sobue G (2011) Diagnosis of sporadic transthyretin Val30Met familial amyloid polyneuropathy: a practical analysis. Amyloid 18(2):53-62

58. Okamoto S, Yamashita T, Ando Y, Ueda M, Misumi Y, Obayashi K, Horibata Y, Uchino M (2008) Evaluation of myocardial changes in familial amyloid polyneuropathy after liver transplantation. Intern Med 47(24):2133-2137. https://doi.org/10.2169/ internalmedicine.47.1399

59. Iorga A, Cunningham CM, Moazeni S, Ruffenach G, Umar S, Eghbali M (2017) The protective role of estrogen and estrogen receptors in cardiovascular disease and the controversial use of estrogen therapy. Biol Sex Differ 8(1):33. https://doi.org/10.1186/ s13293-017-0152-8

60. Arnold AP, Cassis LA, Eghbali M, Reue K, Sandberg K (2017) Sex hormones and sex chromosomes cause sex differences in the 
development of cardiovascular diseases. Arterioscler Thromb Vasc Biol 37(5):746-756. https://doi.org/10.1161/ATVBAHA.116. 307301

61. Ton V-K, Mukherjee M, Judge DP (2015) Transthyretin cardiac amyloidosis: pathogenesis, treatments, and emerging role in heart failure with preserved ejection fraction. Clin Med Insights Cardiol 8(Suppl 1):39-44. https://doi.org/10.4137/CMC.S15719

62. Hellman U, Alarcon F, Lundgren H-E, Suhr OB, Bonaiti-Pellié C, Planté-Bordeneuve V (2008) Heterogeneity of penetrance in familial amyloid polyneuropathy, ATTR Val30Met, in the Swedish population. Amyloid 15(3):181-186. https://doi.org/10.1080/ 13506120802193720

63. Drugge U, Andersson R, Chizari F, Danielsson M, Holmgren G, Sandgren O, Sousa A (1993) Familial amyloidotic polyneuropathy in Sweden: a pedigree analysis. J Med Genet 30(5):388-392. https://doi.org/10.1136/jmg.30.5.388

64. Thompson AE, Anisimowicz Y, Miedema B, Hogg W, Wodchis WP, Aubrey-Bassler K (2016) The influence of gender and other patient characteristics on health care-seeking behaviour: a QUALICOPC study. BMC Fam Pract 17:38. https://doi.org/10. 1186/s12875-016-0440-0

65. Mackenzie CS, Gekoski WL, Knox VJ (2006) Age, gender, and the underutilization of mental health services: the influence of helpseeking attitudes. Aging Ment Health 10(6):574-582. https://doi. org/10.1080/13607860600641200
66. Matheson FI, Smith KLW, Fazli GS, Moineddin R, Dunn JR, Glazier RH (2014) Physical health and gender as risk factors for usage of services for mental illness. J Epidemiol Community Health 68(10):971-978. https://doi.org/10.1136/jech-2014-203844

67. Lang RM, Badano LP, Mor-Avi V, Afilalo J, Armstrong A, Ernande L, Flachskampf FA, Foster E, Goldstein SA, Kuznetsova T, Lancellotti P, Muraru D, Picard MH, Rietzschel ER, Rudski L, Spencer KT, Tsang W, Voigt J-U (2015) Recommendations for cardiac chamber quantification by echocardiography in adults: an update from the American Society of Echocardiography and the European Association of Cardiovascular Imaging. J Am Soc Echocardiogr 28(1):1-39.e14. https://doi.org/10.1016/j.echo.2014. 10.003

68. Maurer MS, Elliott P, Comenzo R, Semigran M, Rapezzi C (2017) Addressing common questions encountered in the diagnosis and management of cardiac amyloidosis. Circulation 135(14):13571377. https://doi.org/10.1161/circulationaha.116.024438

69. Grogan M, Scott CG, Kyle RA, Zeldenrust SR, Gertz MA, Lin G, Klarich KW, Miller WL, Maleszewski JJ, Dispenzieri A (2016) Natural history of wild-type transthyretin cardiac amyloidosis and risk stratification using a novel staging system. J Am Coll Cardiol 68(10):1014-1020. https://doi.org/10.1016/j.jacc.2016.06.033

Publisher's note Springer Nature remains neutral with regard to jurisdictional claims in published maps and institutional affiliations. 